\title{
Influence of QRS Infarct Score and QRS Duration prior to Transcatheter Aortic Valve Replacement on Follow-up Left Ventricular End Systolic Volume in Patients with New Persistent Left Bundle Branch Block
}

\begin{abstract}
Laura G.J. Hannink B.Sc ${ }^{\mathrm{a}, \mathrm{b}}$, Galen S. Wagner, $\mathrm{MD}^{\mathrm{c}}$, Joseph Kisslo, $\mathrm{MD}, \mathrm{PhD}^{\mathrm{c}}$, Fawaz Abdulaziz M Alenezi, MD ${ }^{\mathrm{c}}$ Linda K. Shaw, MS ${ }^{\mathrm{d}}$, Paul Hofmann, BS ${ }^{\mathrm{d}}$, Robbert Zusterzeel, MD ${ }^{\mathrm{e}}$, Matthew Phelan, $\mathrm{MS}^{\mathrm{d}}$, Eric.J. Velazquez, $\mathrm{MD}^{\mathrm{c}}$ Anton P.M Gorgels, MD, $\mathrm{PhD}^{\mathrm{a}}$
\end{abstract}

\footnotetext{
${ }^{a}$ Department of Cardiology, Maastricht University Medical Center, Maastricht, The Netherlands

${ }^{\mathrm{b}}$ Duke Clinical Research Institute, Durham, North Carolina, USA

${ }^{\mathrm{c}}$ Department of Medicine, Division of Cardiology, Duke University Medical Center, Durham, North Carolina, USA

${ }^{\mathrm{d}}$ Department of Statistics, Duke Clinical Research Institute, Durham, North Carolina, USA

${ }^{\mathrm{e}}$ U.S. Food and Drug Administration, Silver Spring, Maryland, USA
}

\section{Wordcount: 2,557}

* Corresponding author: Laura Hannink, B.Sc

Department of Cardiology, Maastricht University Medical Center, Postbus 5800, 6202 AZ Maastricht, The Netherlands. Fax +31 433871720.

E-mail: lgj.hannink@student.maastrichtuniversity.nl 
1 Abstract

2 Background: New-onset left bundle branch block (LBBB) is a known complication during

3 Transcatheter Aortic Valve Replacement (TAVR). This study evaluates the influence of pre-TAVR

4 cardiac conditions on left ventricular functions in patients with new persistent LBBB post-TAVR.

5

6

Results: There was a trend towards a positive correlation between QRS score and LVESV of $\mathrm{r}=0.59$ $(p=0.058)$, while there was no relationship between QRS duration and LVESV $(\mathrm{r}=-0.18[p=0.59])$.

Conclusion: This study showed that patients with new LBBB and higher pre-TAVR QRS infarct score may have worse post-TAVR left ventricular function, however, pre-TAVR QRS duration has no such predictive value. Because of the small sample size these results should be interpreted with caution and assessed in a larger study population.

Keywords: Transcatheter Aortic Valve Replacement, Left Bundle Branch Block, Selvester QRSscore, QRS duration, TAVR, LBBB. 


\section{Introduction}

Symptomatic severe calcific aortic valve stenosis has a high mortality rate $(1,2)$. Transcatheter aortic valve replacement (TAVR) has recently emerged as a therapeutic option for patients who have high mortality risk with conventional surgical treatment(3). Recent studies have shown, however, that TAVR can induce inter-ventricular conduction abnormalities such as left bundle branch block (LBBB) or atrio-ventricular (AV) block(4). The reported incidence of new-onset LBBB after TAVR is between 16-40\%(5), while complete AV-block occurs in 6-13\% of patients(6, 7). LBBB causes

dyssynchronous left ventricular contraction that potentially compromises left ventricular function $(8$, 9). It was also shown that patients who developed new LBBB after TAVR are at higher risk for allcause mortality,(9) especially for those whom this LBBB persisted in about $12 \%$ of cases after hospital discharge(10).

Patients with new persistent LBBB have continuous dyssynchronous contractions that, unless compensated, can lead to dilation of the left ventricle (LV) and clinical development of heart failure(11). However, it is unknown which pre-TAVR cardiac conditions are predictive of poor compensation for this dyssynchronous LV contraction caused by new-onset LBBB. These patients may have concomitant coronary artery disease, and the presence, location, and amount of myocardial scar pre-TAVR may have an influence on their compensation mechanisms. Also, a variable amount of left ventricular hypertrophy (LVH) has already occurred as compensation for the systolic overloading of aortic stenosis(1). Calculated LV mass has a higher predicted value for detecting LVH than left ventricular wall thickness(12), and it would be interesting to know if patients with a higher pre-TAVR left ventricular mass (LVM) are more likely to compensate for new persisting LBBB.

We investigated the predictive values of pre-TAVR LV scar (estimated by QRS score) and LV mass (estimated by QRS duration). We tested the hypotheses that there are correlations between preTAVR higher Selvester QRS scores and/or longer QRS duration and an increase in left ventricular end-systolic volume (LVESV) at 6-12 months follow up. 


\section{Methods}

Study population

This is a retrospective study, utilizing information from Duke University Medical Center clinical databases, between April 2011 and May 2014. The Duke Cardiovascular Disease Database, the Duke Echocardiology Lab and hospital administrative resources provided data for these assessments. The study was approved by the Duke University Institutional Review Board.

To be included in this study, patients were required to have a TAVR procedure with either Edwards SAPIEN"M valve or Corevalve ${ }^{\mathrm{TM}}$. They also received both pre-interventional screening and 6-12 months post-interventional follow-up ECGs and echocardiography studies. The QRS complexes on the post-TAVR ECGs had to meet the strict LBBB criteria, proposed by Strauss $(13)(\mathrm{n}=22)$. Exclusion criteria were LBBB on ECG before TAVR $(n=3)$, atrial fibrillation on ECG (n=3), lack of a pair of echocardiograms of sufficient quality to determine outcome $(n=2)$ and atrial fibrillation on the echocardiogram post-TAVR $(n=3)$. Eleven patients met the inclusion criteria for this study.

\section{Electrocardiographic analysis}

Standard resting 12-lead ECGs $(0.5-150 \mathrm{~Hz}, 25 \mathrm{~mm} / \mathrm{s}, 10 \mathrm{~mm} / \mathrm{mV})$ were evaluated for strict LBBB(13), Selvester QRS score(14), and QRS duration from three periods of time: the ECGs preTAVR, immediately post-TAVR and at 6-12 months follow up. We used the electronically determined QRS duration and confirmed it manually. ECGs were analyzed by two independent investigators (LH, GW) who were blinded to any echocardiographic data. Disagreements were resolved by consensus.

\section{Strict $L B B B$}

For the evaluation of LBBB we used the criteria for strict LBBB by Strauss et al(13). These criteria include: QS or $\mathrm{rS}$ in lead V1, QRS duration of $\geq 140 \mathrm{~ms}$ in men and $\geq 130 \mathrm{~ms}$ in women, and mid-QRS notch/slurring in $\geq 2$ leads of $\mathrm{V}_{1}-\mathrm{V}_{2}, \mathrm{~V}_{5}-\mathrm{V}_{6}$, and/or I-aVL. 
Selvester QRS Score

The modified Selvester QRS scores were used for estimating myocardial scar location and size, depending on the presence of confounding factors(14). Of a maximum of 31 points that can be given, each point resembles 3\% infarct of the left ventricular myocardium. Presence of left ventricular hypertrophy was also evaluated based on the Romhilt-Estes criteria, since these criteria evaluate multiple aspects (e.g. QRS duration) of the ECG(15).

\section{Echocardiographic analysis}

Complete standard resting 2-dimensional (2D) and Doppler echocardiograms were performed on all patients, as a part of standard clinical care. The echocardiograms retrieved were pre-TAVR, and after 6-12 months post-TAVR. A single experienced reader, blinded to ECG findings, measured all echocardiograms for analysis (FA). Baseline measurements included: septal wall thickness (SWT), left ventricle end diastolic dimension (LVEDD), posterior wall thickness (PWT), left ventricle end systolic dimension (LVESD) and the mean measurement (from apical 2-chamber and apical 4-chamber) for left ventricular end-systolic volume (LVESV), left ventricular end-diastolic volume (LVEDV) and aortic valve peak pressure gradient (AVP PPG). Also, all post-TAVR echocardiograms were evaluated for AVP PPG, new abnormalities in wall motion other than caused by LBBB and paravalvular/valvular aortic regurgitation. LVESV was used as the outcome variable for determining left ventricular function, as LVESV has been shown to correlate with impaired left ventricular function, based on an analysis by White et al.(16) LVESV was calculated using the biplane method of discs (modified Simpson's rule) in the apical 2- and 4-chamber views at end systole, as recommended by the American Society of Echocardiography(12).

\section{Statistical analysis}

Baseline characteristics are presented in absolute numbers and as a percentage of the study population. Continuous variables are displayed as mean, median, interquartile range (IQR) and standard deviation (SD) where appropriate. In order to detect left ventricle change over time, we used the delta $(\Delta)$ LVESV from baseline and 6-12 months follow up echocardiogram measurements. The 
Spearman's correlation coefficient was used to measure the association between QRS scoring/QRS duration and $\triangle \mathrm{LVESV}$ separately. A linear regression model was generated to further assess the relationship between the variables and outcomes. All calculations were performed using SAS version 9.4 (Cary, NC, USA).

\section{Results}

\section{Patient characteristics}

Table 1 shows the baseline characteristics of the study population before TAVR. From the 11 patients who were included, 7 were male and 4 female, with a mean age of $81 \pm 7.7$ years. The mean QRS score pre-TAVR was $2.4 \pm 2.6$ points, QRS duration $104 \pm 12.5 \mathrm{~ms}$ and LVESV $37 \pm 25.3 \mathrm{~mL}$. The time between pre-TAVR ECG and TAVR procedure varied from 3 months up to a couple of hours before the procedure while the pre-TAVR echo varied from 2 months till 2,5 weeks before the procedure. The follow-up ECGs and echocardiograms were performed 6 to 8 months after TAVR.

Considering confounding factors that were used in evaluating Selvester QRS score, there was 1 patient who had left anterior fascicular block (LAFB) on ECG and 1 patient LVH. The changes in parameters from baseline to post-TAVR are shown in Table 2.

All follow-up echocardiograms ( $\mathrm{n}=11)$ were negative for other new wall motion abnormalities other than those caused by LBBB. Two patients (18.2\%) had a mild degree of paravalvular aortic regurgitation.

\section{QRS score and LVESV}

The relationship between baseline Selvester QRS score and the change in LVESV from baseline to follow-up echo (6-12 months) is presented in Figure 1a. The QRS score in this study population varied from $0-6$ points $(0-18 \% \mathrm{LV}$ scar). The range of $\Delta$ LVESV varied from $-47 \mathrm{~mL}-+$ $32 \mathrm{~mL}$. There was a non-significant trend towards a larger change in LVESV with a higher QRS score $(\mathrm{r}=0.59[p=0.058])$. A linear regression model was examined to further explore the relationship between QRS score and change in LVESV ( $\triangle$ LVESV $=-5.03+5.26 *$ QRS score). In this small study, the parameter estimate of $5.26(p=0.08)$ suggests that an increase in QRS Score by 1 point 
increases the change in LVESV by $5.26 \mathrm{~mL}$.

Because of the distribution of Selvester QRS scores (0-2 and 5-6 points), the patients were divided into two groups as shown in Figure 1b. The patient group with a QRS score of 0-2 points $(\mathrm{n}=7)$ had an average decrease of $0.5 \mathrm{ml}$ in LVESV, but the patient group with a QRS score of 5-6 points $(\mathrm{n}=4)$ had an average increase of $21.5 \mathrm{ml}$. The difference of the QRS score group averages was $21 \mathrm{ml}$ and had an associated p-value of 0.158 .

\section{QRS duration and LVESV}

The relationship between baseline QRS duration on ECG and the change in LVESV during follow-up from baseline is presented in Figure 2a. The baseline QRS duration in this study population varied from $82 \mathrm{~ms}$ to $122 \mathrm{~ms}$. The $\Delta$ LVESV varied from $-47 \mathrm{~mL}$ to $+32 \mathrm{~mL}$. There was a negative non-significant relation between these two variables of $\mathrm{r}=-0.18(p=0.59)$. A linear regression model was examined to further describe the relationship between QRS duration and change in LVESV ( $\Delta$ LVESV $=87.12+-0.77 *$ QRS duration). In this small study, the parameter estimate of -0.77 ( $p=$ 0.24) suggests that an increase in QRS duration by $1 \mathrm{~ms}$ decreases the change in LVESV by $0.77 \mathrm{~mL}$. There was no clear grouping of QRS duration in this study population. Therefore, we divided the population into two groups and set the threshold at $110 \mathrm{~ms}$ (Figure 2b). The group of patients $(\mathrm{n}=8)$ with a $\mathrm{QRS}$ duration of $\leq 110 \mathrm{~ms}$ showed an average increase of $16 \mathrm{ml}$, whereas the patient group ( $\mathrm{n}=3$ ) with a $\mathrm{QRS}$ duration of $\geq 111 \mathrm{~ms}$ showed an average change of $-16 \mathrm{ml}$ in LVESV. The difference of the QRS duration group averages was $32 \mathrm{ml}$ and had an associated p-value of 0.054 .

\section{Discussion}

This study, which included patients with new persistent LBBB after TAVR, gives us some insight of the influence of pre-TAVR ECG characteristics on left ventricular dilation during follow up. The results that represented the first hypothesis demonstrated that patients with a higher Selvester QRS score, compared with patients who had a lower QRS score, may have greater increase in LVESV during follow-up. The results that represented the second hypothesis, showed that patients with a longer QRS duration (>110 ms) may have an average decrease in LVESV post-TAVR, compared to 
the patients with a shorter QRS duration $(<110 \mathrm{~ms})$, who had an average increase in LVESV. There was a marked decrease of LVESV in the first group, which might indicate improvement of LV function. Due to the small sample available for this assessment, these study results should be considered descriptive and statistics interpreted with caution. The results can be used to generate further hypotheses to be tested in a larger study population.

The fact that a higher QRS score may result in a greater increase of LVESV can indicate the worsening of left ventricular function and may therefore predict LV function after TAVR(16). This can possibly be explained by a failure of the LV to compensate for new persistent LBBB post-TAVR. A myocardial scar results in dysfunction of the heart muscle to contract in the area where the scar is located. Since these patients already have a possible impaired function of their left ventricle, it is imaginable that patients with a higher amount of scarring, can't compensate as well for the dyssynchronous contractions of the left ventricle than patients with no or a low amount of scarring. The secondary hypothesis was based on the premise that patients with a higher QRS duration have more muscle reserve compared with patients who have a lower QRS duration because they have a higher LV mass. Even though QRS duration is not an ideal marker for LV mass, it has been shown to be associated with LV mass in patients with cardiomyopathy, in either normal conduction or LBBB(17) and those undergoing TAVR(18). It can therefore be assumed that an increased LVM leads to longer transmural activation time, and could be represented on standard ECG as prolonged QRS duration(17). In addition, a higher LV mass might be a factor that would improve the ability to compensate for LBBB. However, even though there was the observation of a reduction in LVESV with longer QRS duration, the fact that it was non-significant may also mean that a new persistent LBBB only has a minor effect on LVESV since patients already have a compromised LV function before their TAVR procedure or that other factors affect QRS duration in this patient population. Other post-TAVR echocardiographic findings (aortic regurgitation and decreased wall motion) that could potentially increase LVESV post-TAVR were also considered. Aortic regurgitation is an important factor that can cause volume overload in the left ventricle, and therefore an increased LVESV. Only a minority of this study population had a mild degree of paravalvular aortic regurgitation post-TAVR. 
anatomical location of the left bundle branch. In most cases, the main left bundle branch penetrates the membranous portion of the interventricular septum on the most leftward side, under the aortic ring. Therefore, when performing TAVR, it is possible that the left bundle branch becomes manipulated by excessive pressure, in a way that will cause mechanical stress and can eventually disturb the anatomic pathway of the left bundle branch $(4,19)$.

Previous studies, such as the PARTNER trial(20) have shown that there might be pre-TAVR patient characteristics, such as poor functional capacity (walk distance) and lower mean aortic valve gradient, that could influence outcomes in terms of death and quality of life (QoL). However, there are no previous studies that specifically evaluated the effect of possible pre-procedural predictors on outcome of left ventricular functions in patients with new-onset LBBB. Performing studies such as this one is important since results may have implications for clinical treatment. For example, to prevent dilated cardiomyopathy in high-risk patients caused by failed compensation for LBBB, early use of cardiac resynchronization therapy (CRT) can restore dyssynchronous left ventricular contractions in patients with LBBB and thus improve left ventricular function.

\section{Suggestions for Future Studies}

In future studies, a control group of patients with no new persistent LBBB is needed to verify if the Selvester QRS score in itself is already a predictive factor for failed compensation of left ventricular function after TAVR. Furthermore, it is known that between 5-39\% of patients undergoing TAVR are in need for a permanent pacemaker implantation (PPI)(21, 22). Right ventricular paced rhythms will however cause a LBBB pattern on ECG. If a significant result can be detected in this future study, it is recommended to also investigate this group of patients for possible predictive ECG factors such as QRS score and/or QRS duration. Furthermore, future studies should assess other endpoints such as diastolic function parameters, heart failure and exercise endpoints as well as mortality. 


\section{Limitations}

The primary limitation of this study is a small sample size, due to strict inclusion- and exclusion criteria. Also, although we chose a follow-up period of 6-12 months in this study, it is possible that after this follow-up period a larger change could have occurred in the remodeling of the left ventricle that would lead to a possible larger change in LVESV.

\section{Conclusions}

The results of this study showed that patients with a higher pre-TAVR Selvester QRS-score (5-6 points) may have a worse LV function after TAVR in the presence of new LBBB. This can be caused by higher scar burden detrimental to possible compensation for the LBBB. The results showed no correlation between QRS duration and a change in LVESV. However, the steepness of the slope suggests that a longer QRS duration could be associated with a decrease in LVESV. Larger studies should further evaluate the effect of QRS score and QRS duration on left ventricular function in patients with new persistent LBBB after TAVR. 
2 This study was supported by a research fellowship from the Oak Ridge Institute of Science and

3 Education through an interagency agreement between the U.S. Department of Energy and the FDA.

4

\section{Disclaimer}

6 The mention of commercial products, their sources, or their use in connection with material reported

7 herein is not to be construed as either an actual or implied endorsement of such products by the

8 Department of Health and Human Services.

9

10 


\section{References}

1. Rader F, Sachdev E, Arsanjani R, Siegel RJ. Left ventricular hypertrophy in valvular aortic stenosis mechanisms and clinical implications. Am J Med. 2014.

2. Spaccarotella C, Mongiardo A, Indolfi C. Pathophysiology of aortic stenosis and approach to treatment with percutaneous valve implantation. Circ J. 2011;75(1):11-9.

3. Poels TT, Houthuizen P, Van Garsse LA, Maessen JG, de Jaegere P, Prinzen FW. Transcatheter aortic valve implantation-induced left bundle branch block: Causes and consequences. J Cardiovasc Transl Res. 2014;7(4):395-405.

4. Colombo A, Latib A. Left bundle branch block after transcatheter aortic valve implantation. J Am Coll Cardiol. 2012;60(18):1753-5.

5. Van der Boon RM, Nuis RJ, Van Mieghem NM, Jordaens L, Rodés-Cabau J, van Domburg RT, et al. New conduction abnormalities after TAVI — frequency and causes. Nat Rev Cardiol. 2012;9(8):454-63.

6. Sinhal A, Altwegg L, Pasupati S, Humphries KH, Allard M, Martin P, et al. Atrioventricular block after transcatheter balloon expandable aortic valve implantation. JACC Cardiovasc Interv. 2008 June;1(3):305-9.

7. Akin I, Kische S, Paranskaya L, Schneider H, Rehders TC, Trautwein U, et al. Predictive factors for pacemaker requirement after transcatheter aortic valve implantation. BMC Cardiovasc Disord. 2012;12(1):87.

8. Hoffmann R, Herpertz R, Lotfipour S, Aktug Ö, Brehmer K, Lehmacher W, et al. Impact of a new conduction defect after transcatheter aortic valve implantation on left ventricular function. JACC Cardiovasc Interv. 2012;5(12):1257-63.

9. Houthuizen P, Van Garsse LA, Poels TT, de Jaegere P, van der Boon RM, Swinkels BM, et al. Left bundle-branch block induced by transcatheter aortic valve implantation increases risk of death. Circulation. 2012;126(6):720-8.

10. Urena M, Webb JG, Cheema A, Serra V, Toggweiler S, Barbanti M, et al. Impact of new-onset persistent left bundle branch block on late clinical outcomes in patients undergoing transcatheter aortic valve implantation with a balloon-expandable valve. JACC Cardiovasc Interv. 2014;7(2):128-36.

11. Zannad F, Huvelle E, Dickstein K, van Veldhuisen DJ, Stellbrink C, Køber L, et al. Left bundle branch block as a risk factor for progression to heart failure. Eur J Heart Fail. 2007;9(1):7-14.

12. Lang RM, Bierig M, Devereux RB, Flachskampf FA, Foster E, Pellikka PA, et al. Recommendations for chamber quantification: A report from the american society of echocardiography's guidelines and standards committee and the chamber quantification writing group, developed in conjunction with the european association of echocardiography, a branch of the european society of cardiology. J Am Soc Echocardiogr. 2005 December;18(12):1440-63.

13. Galeotti L, van Dam PM, Loring Z, Chan D, Strauss DG. Evaluating strict and conventional left bundle branch block criteria using electrocardiographic simulations. Europace. 2013;15(12):1816-21. 
14. Loring Z, Chelliah S, Selvester RH, Wagner G, Strauss DG. A detailed guide for quantification of myocardial scar with the selvester QRS score in the presence of electrocardiogram confounders. J Electrocardiol. 2011;44(5):544-54.

15. Melvin D, Shah BR, Maynard C, Bart BA, Wagner GS. Left ventricular hypertrophy impairs detection of myocardial infarction in patients with nonischemic cardiomyopathy. N C Med J. 1997;58(2):7.

16. White HD, Norris RM, Brown MA, Brandt PW, Whitlock RM, Wild CJ. Left ventricular endsystolic volume as the major determinant of survival after recovery from myocardial infarction. Circulation. 1987;1(76):51.

17. Chan DD, Wu KC, Loring Z, Galeotti L, Gerstenblith G, Tomaselli G, et al. Comparison of the relation between left ventricular anatomy and QRS duration in patients with cardiomyopathy with versus without left bundle branch block. Am J Cardiol. 2014;113(10):1717-22.

18. Sjöberg S, Sundh F, Schlegel T, Maynard C, Rück A, Wagner G, et al. The Relationship between Electrocardiographic Left Ventricular Hypertrophy Criteria and Echocardiographic Mass in Patients undergoing Transcatheter Aortic Valve Replacement. J Electrocardiol. 2015.

19. Piazza N, de Jaegere P, Schultz C, Becker AE, Serruys PW, Anderson RH. Anatomy of the aortic valvar complex and its implications for transcatheter implantation of the aortic valve. Circ Cardiovasc Interv. 2008;1(1):74-81.

20. Arnold SV, Reynolds MR, Lei Y, Magnuson EA, Kirtane AJ, Kodali SK, et al. Predictors of poor outcomes after transcatheter aortic valve replacement: Results from the PARTNER (placement of aortic transcatheter valve) trial. Circulation. 2014;129(25):2682-90.

21. Siontis GC, Jüni P, Pilgrim T, Stortecky S, Büllesfeld L, Meier B, et al. Predictors of permanent pacemaker implantation in patients with severe aortic stenosis undergoing TAVR. J Am Coll Cardiol. 2014;64(2):129-40.

22. Steinberg BA, Harrison JK, Frazier-Mills C, Hughes GC, Piccini JP. Cardiac conduction system disease after transcatheter aortic valve replacement. Am Heart J. 2012;164(5):664-71. (2)

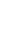
年 . 


13

\section{Figure legends}

Figure 1a: Correlation between $\triangle \mathrm{LVESV}$ in $\mathrm{mL}$ and QRS score.

Figure 1b: Two groups of QRS score (0-2 points and 5-6 points) and the average $\triangle$ LVESV in $\mathrm{mL}$. $P=0.158$ for difference between the two groups.

Figure 2a: Correlation between $\triangle$ LVESV in $\mathrm{mL}$ and pre-TAVR QRS duration

8

Figure $2 b$ : Different groups of pre-TAVR QRS duration and the average $\triangle$ LVESV in $\mathrm{mL} . P=0.054$ for difference between the two groups.

(1)

2

4


Table 1 - Baseline characteristics of the study population

\begin{tabular}{|c|c|}
\hline Variables & $\mathbf{N}=\mathbf{1 1}$ \\
\hline Male, n (\%) & $7(63.6 \%)$ \\
\hline \multicolumn{2}{|l|}{ Age (years), } \\
\hline Median (IQR) & $81(13.3)$ \\
\hline Mean \pm SD & $81 \pm 8.1$ \\
\hline Previous MI, n (\%) & $3(27.3 \%)$ \\
\hline Hypertension, n (\%) & $10(90.9 \%)$ \\
\hline \multicolumn{2}{|l|}{ ECG: } \\
\hline No confounders*, n (\%) & $9(81.8 \%)$ \\
\hline LAFB, n (\%) & $1(9.1 \%)$ \\
\hline $\mathrm{LVH}^{*}, \mathrm{n}(\%)$ & $1(9.1 \%)$ \\
\hline \multicolumn{2}{|l|}{ QRS score (points), } \\
\hline Median (IQR) & $1(5)$ \\
\hline Mean \pm SD & $2.4 \pm 2.6$ \\
\hline \multicolumn{2}{|l|}{ QRS duration,(ms) } \\
\hline Median (IQR) & $106(26)$ \\
\hline Mean \pm SD & $104 \pm 12.5$ \\
\hline \multicolumn{2}{|l|}{ Echo $^{\circ}:$} \\
\hline \multicolumn{2}{|l|}{ SWT $(\mathrm{cm})$, } \\
\hline Median (IQR) & $1.5(0.6)$ \\
\hline Mean \pm SD & $1.5 \pm 0.3$ \\
\hline \multicolumn{2}{|l|}{ LVEDD (cm), } \\
\hline Median (IQR) & $4.3(0.8)$ \\
\hline Mean \pm SD & $4.5 \pm 0.7$ \\
\hline \multicolumn{2}{|l|}{ PWT (cm), } \\
\hline Median (IQR) & $1.3(0.3)$ \\
\hline Mean \pm SD & $1.3 \pm 0.3$ \\
\hline \multicolumn{2}{|l|}{$\operatorname{LVESD}(\mathrm{cm})$} \\
\hline Median (IQR) & $3.5(1.6)$ \\
\hline Mean \pm SD & $3.2 \pm 0.9$ \\
\hline \multicolumn{2}{|l|}{ LVEDV $(\mathrm{ml})^{\wedge}$} \\
\hline Median (IQR) & $96.5(49.2)$ \\
\hline Mean \pm SD & $99 \pm 34.7$ \\
\hline \multicolumn{2}{|l|}{ LVESV (ml)^, } \\
\hline Median (IQR) & $25(34.7)$ \\
\hline Mean \pm SD & $37 \pm 26.5$ \\
\hline \multicolumn{2}{|l|}{ AVP PPG (mmHg), } \\
\hline Median (IQR) & $69(13.0)$ \\
\hline Mean \pm SD & $71 \pm 16.1$ \\
\hline
\end{tabular}

* Determined based on Romhilt-Estes scoring system(15)

${ }^{\circ}$ Estimated average from $\mathrm{N}=11$ patients

${ }^{\wedge}$ Estimated average from the apical 2- and 4-chamber echocardiographic measurement $\mathrm{IQR}=$ Interquartile range; $\mathrm{MI}=$ myocardial infarction; $\mathrm{LAFB}=$ Left anterior fascicular block; $\mathrm{LVH}=\mathrm{Left}$ ventricular hypertrophy; SWT $=$ Septal wall thickness; LVEDD = Left ventricular end-diastolic diameter; PWT $=$ Posterior wall thickness; LVESD $=$ Left ventricular end-systolic diameter; LVEDV $=$ Left ventricular end-diastolic volume; LVESV = Left ventricular end-systolic volume; AVP PPG = Aortic valve peak pressure gradient. 
Table 2-Overall ECG and echo variables pre- and post-TAVR.

Variables

ECG:

LBBB, n (\%)

QRS duration,(ms) Median (IQR) Mean \pm SD

Echo $^{\circ}$ :

LVESV (ml) ,

Median (IQR)

Mean \pm SD
Pre-TAVR $(n=11)$

$0(0 \%)$

106 (26)

$104 \pm 12.5$

25 (34.7)

$37 \pm 26.5$
Post-TAVR (n=11)

$11(100 \%)$

154 (12)

$156 \pm 11.9$

+52 (26)

$+52.0 \pm 16.0$

\section{Change}

4

5

6

7

8

9

10

11

12

13

14

15

16

17

18

19

20

21

22

23

24 
1

2

1 a.

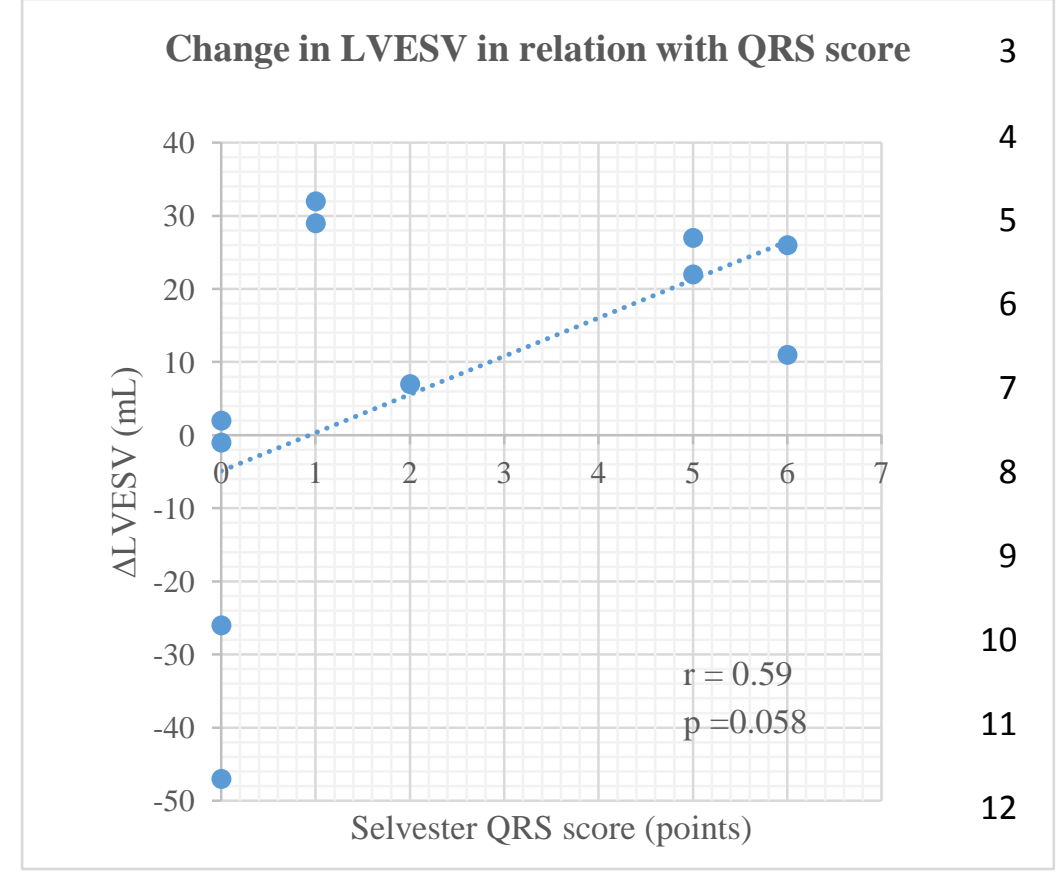

13

14

15

$1 b$.

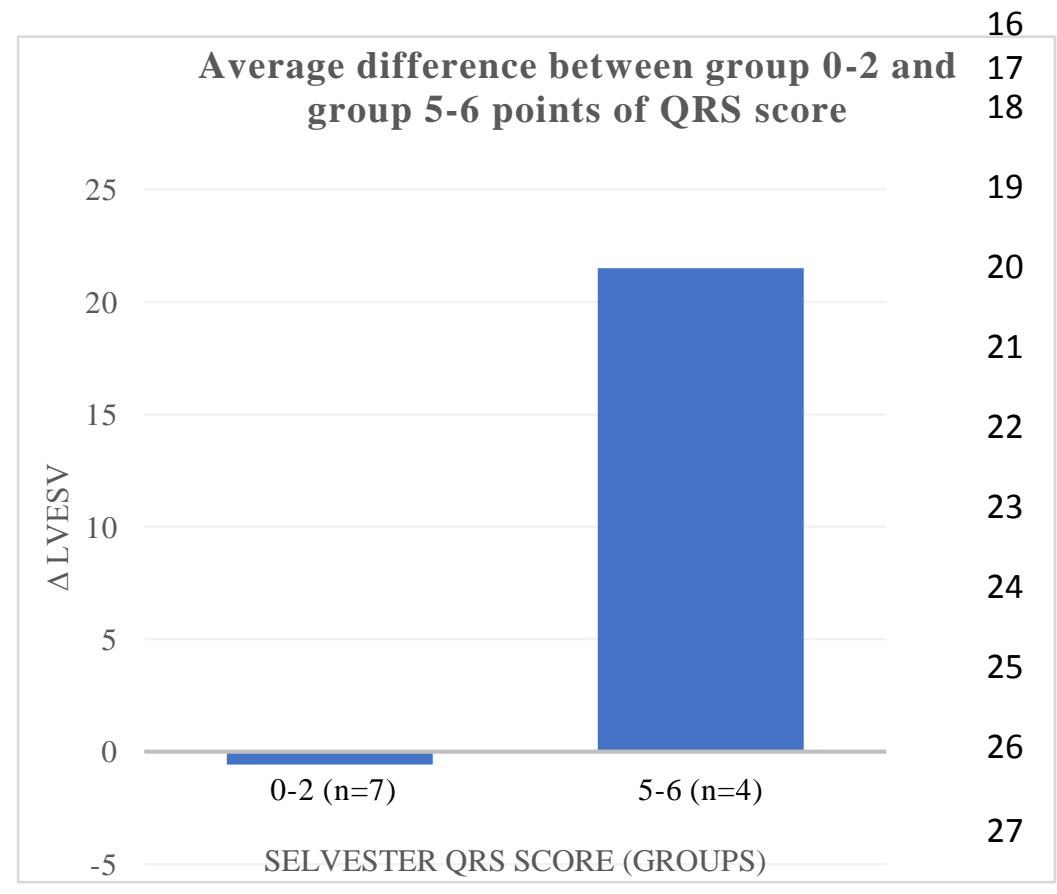

28

29

30

31 
$2 \mathbf{a .}$

2

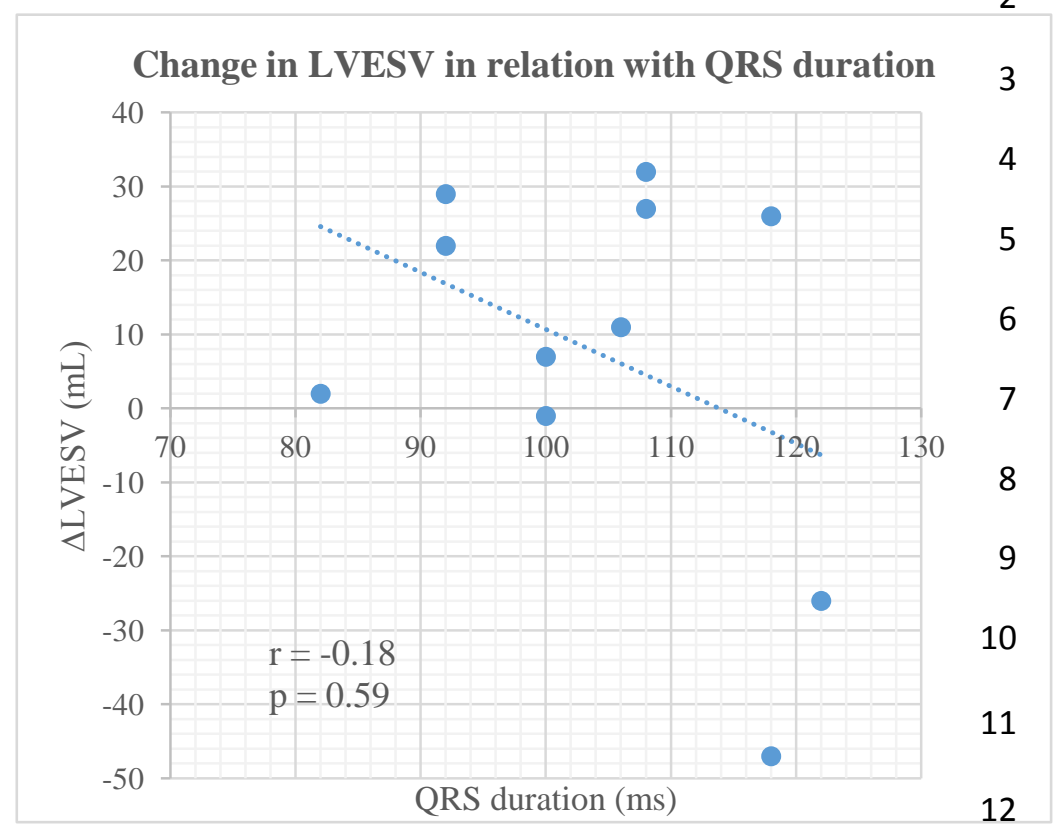

13

14

15

16

17

18

19

20

21

22

23

24

25

26

27

28

29

30

31

32

\section{Averange difference of $\triangle \mathrm{LVESV}$ in relation} to QRS duration (groups)

20

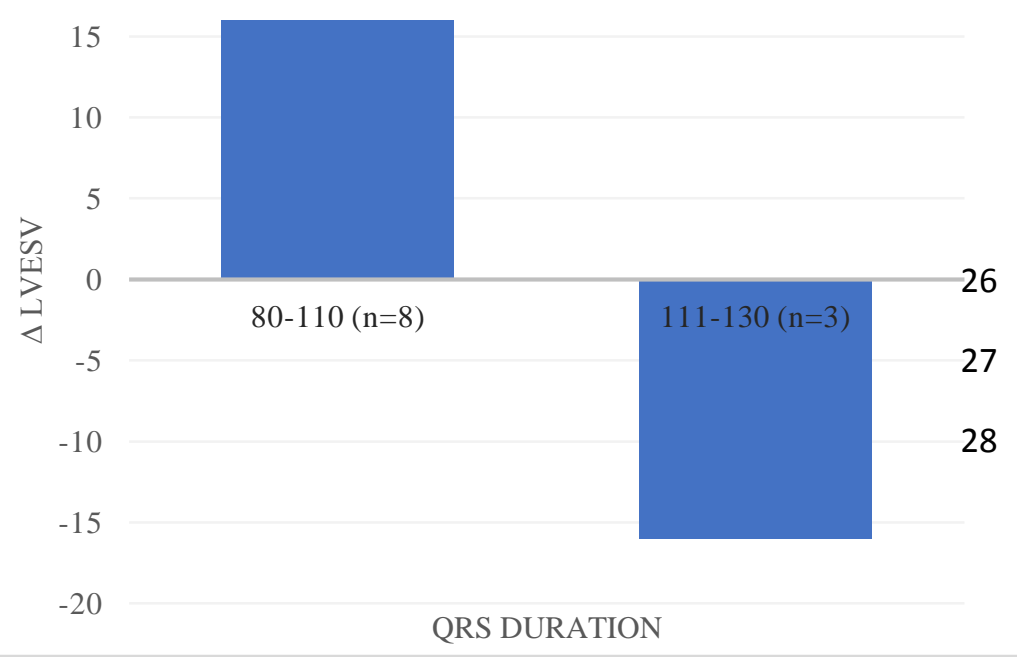

